\title{
Comparison of the Effect of Two Driving Retraining Programs on On-Road Performance After Stroke
}

\author{
Hannes Devos, MSc, Abiodun Emmanuel Akinwuntan, PhD, Alice Nieuwboer, PhD, Mark Tant, PhD, \\ Steven Truijen, PhD, Liesbet De Wit, PhD, Carlotte Kiekens, MD, and Willy De Weerdt, PhD
}

\begin{abstract}
Background. Several driving retraining programs have been developed to improve driving skills after stroke. Those programs rely on different rehabilitation concepts. Objectives. The current study sought to examine the specific carryover effect of driving skills of a comprehensive training program in a driving simulator when compared with a cognitive training program. Methods. Further analysis from a previous randomized controlled trial that investigated the effect of simulator training on driving after stroke. Forty-two participants received simulator-based driving training, whereas 41 participants received cognitive training for 15 hours. Overall performance in the on-road test and each of its 13 items were compared between groups immediately posttraining and at 6 months poststroke. Results. Generalized estimating equation analysis showed that the total score on the on-road test and each item score improved significantly over time for both groups. Those who received driving simulator training achieved better results when compared with the cognitive training group in the overall on-road score and the items of anticipation and perception of signs, visual behavior and communication, quality of traffic participation, and turning left. Most of the differences in improvement between the 2 interventions were observed at 6 months poststroke. Conclusions. Contextual training in a driving simulator appeared to be superior to cognitive training to treat impaired on-road driving skills after stroke. The effects were primarily seen in visuointegrative driving skills. Our results favor the implementation of driving simulator therapy in the conventional rehabilitation program of subacute stroke patients with mild deficits.
\end{abstract}

Keywords: Stroke; Rehabilitation; Automobile driving; Driving simulator

$S^{t}$ troke survivors often suffer from motor, visual, and cogniive problems that might impair their ability to resume driving. ${ }^{1-5}$ About $40 \%$ to $50 \%$ of stroke drivers do not pass an official fitness to drive assessment. ${ }^{3-6}$ Poststroke survivors who are obliged to give up driving are less likely to be involved in social activities and have a higher risk of depression. ${ }^{7,8}$ Driving retraining programs are therefore needed.

Only 2 randomized controlled trials (RCTs) have been conducted to examine whether driving skills can be retrained after stroke. ${ }^{9,10}$ Mazer et $\mathrm{al}^{9}$ focused on the cognitive training of a component of driving ability. All participants received 20 sessions of visual attention training. The experimental group was trained using the useful field of view (UFOV) analyzer, ${ }^{11}$ whereas the control group received traditional visuoperception training. Results revealed no significant differences between the groups in on-road driving performance and visuoperceptual tasks after training, except in the UFOV, which was in favor of the experimental group. ${ }^{9}$ This difference in improvement in the
UFOV test was due rather to a test effect than to an actual learning effect. The RCT by Akinwuntan et $\mathrm{al}^{10}$ focused on a more comprehensive training program. Participants received 15 sessions of either contextual training in a driving simulator or cognitive training using off-the-shelf games. At 6 months poststroke, $73 \%$ of the participants of the simulator group were allowed to resume driving in contrast to $42 \%$ of the cognitive group. The authors concluded that driving simulator therapy favors the outcome on an official driving fitness evaluation. ${ }^{10}$

However, it remained unclear how driving simulator therapy positively affected on-road performance. The on-road test is regarded as the most important determinant in the decision regarding fitness to drive. ${ }^{12}$ In most countries, it is even the sole criterion of driving fitness. ${ }^{1-4,13,14}$ Therefore, we aimed to determine the specific effects of simulator versus cognitive training on on-road performance after stroke. We hypothesized that training in a task-related context would result in more specific transfer of on-road driving skills than cognitive training.

From the Department of Rehabilitation Sciences, Faculty of Kinesiology and Rehabilitation Sciences, Katholieke Universiteit Leuven, Leuven, Belgium (HD, AN, LDW, WDW); Department of Physical Therapy, School of Allied Health Sciences, Medical College of Georgia, Augusta, Georgia (AEA); CARA Department, Belgian Road Safety Institute, Brussels (MT); Department of Health Care Sciences, Institute for Physiotherapy and Occupational Therapy, University College of Antwerp, Antwerp (ST); and the Department of Physical Medicine and Rehabilitation, University Hospital Leuven Campus Pellenberg, Leuven (CK), Belgium. Address correspondence to Hannes Devos, MSc, Katholieke Universiteit Leuven, Department of Rehabilitation Sciences, Tervuursevest 101, Post Box 1501, BE-3001 Leuven, Belgium. E-mail: Hannes.Devos@faber.kuleuven.be. 


\section{Methods}

\section{Subjects}

In the RCT by Akinwuntan et al, ${ }^{10}$ study participants were recruited from the rehabilitation unit of the University Hospital Pellenberg in Belgium. First-ever subacute stroke patients who were $\leq 75$ years old, had a valid driver's license, and had a history of active driving before stroke onset were included. In accordance with Belgian law, stroke participants who had an epileptic seizure in the 6 months prior to inclusion were excluded. ${ }^{15}$ Belgian law also stipulates that stroke survivors are not allowed to resume driving until at least 6 months after stroke onset and after a positive advice by a neurologist or an official driving assessment center. ${ }^{15}$ Therefore, all participants did not have any on-road driving experience during the study period. A priori power analysis revealed that a sample size of 72 participants was needed to achieve an $80 \%$ chance and an $\alpha$ level of .05 to detect a median effect size of .50 between groups in the on-road test. ${ }^{10}$

\section{Baseline Clinical Assessments}

At intake into the hospital, participants' characteristics such as age, sex, education, side of lesion, and type of stroke (documented by computed tomography scans and magnetic resonance imaging) and driving history were recorded. The clinical neurological examination involved the evaluation of visual field loss and visual or tactile inattention. The presence of visual field deficits was determined by a clinical visual confrontation test with moving fingers for each eye and for double simultaneous stimulation. Assessments included the Barthel Index ${ }^{16}$ and the Mini-Mental State Examination (MMSE) ${ }^{17}$

\section{Intervention}

All participants received a total of 15 training sessions of 1 hour at a rate of 3 sessions per week in addition to the regular hospital rehabilitation. Participants were randomly allocated to 2 intervention groups as described earlier. ${ }^{10}$

Participants in the simulator group were trained in a stationary full-bodied Ford Fiesta 1.8 with automatic gear transmission and all its original mechanical parts. Subjects with severe hemiparesis were taught to use car adaptations such as left-sided accelerator pedal, right-sided indicator stick, and steering knob to compensate for their loss of functioning. Life-size computergenerated images were projected on a flat screen with a horizontal visual angle of $45^{\circ}$. Tailor-made, interactive driving scenarios were developed using the "Scenario Definition Language" from STISIM Drive System (version 1.03; Systems Technology Inc, Hawthorne, CA). Before training, a 3-km-long scenario was used to acquaint participants with the driving simulator, adaptive aids, and the road scenarios.

Twelve 5-km simulator scenarios were developed to train 6 specific driving skills. Scenarios 1 and 2 trained positioning on straight and curvy roads at different speeds. In scenarios 3 and 4, participants learned to adapt their speed and make complete stops at zebra crossings. In scenarios 5 and 6, anticipatory skills were trained with children unexpectedly crossing the road. Scenarios 7 and 8 trained overtaking maneuvers at high speed. Scenarios 9 and 10 focused on training perceptual skills by asking the participants to verbally respond to different road signs. In training scenarios 11 and 12 , hazard perception and judgment was trained by presenting different on-road accident scenes. Participants needed to decide whether it was safe to change lanes. Each skill was first trained in a scenario that simulated regular day-to-day traffic. Afterward, the same scenarios were presented but with distracters meant to train participants' ability to divide attention during driving. The distracters were 2 red-shaped diamonds displayed at the edge of the left and right sides of the screen. When the diamonds changed into a triangle pointing to the left or right, participants needed to signal in the indicated direction as fast as possible. Participants were asked to blow the horn when either of the symbols changed to a horn sign. Additionally, four $5-\mathrm{km}$ scenarios representing a straight bare road, with the same distracters as described above, trained divided attention skills under simple conditions. Participants were trained in the first scenario condition until it was determined by the trainer that they could handle the scenario with the distracters. If participants failed in any of the test sessions, they were first given the opportunity to self-identify the problem and possible solution. If the problem could not be identified, the trainer told the participants what the problem was, suggested a way to overcome the problem, and allowed them to try again.

Participants in the cognitive group received driving training using commercially available games involving cognitive skills that have been reported necessary for driving. "Rush Hour" from Binary Arts trained problem-solving and visuospatial abilities. The aim was to slide cars and trucks in different directions until the path was cleared for a target red car to drive out. It involved 40 cards of different complexity, and each participant successfully completed the preceding level before progressing to the next one. "Tantrix" was used to train visuospatial skills, nonverbal memory, and planning ability. The goal was to form the longest line or leap of the individual's own color, while at the same time attempting to restrict the other players' progress. "Take It Easy" by Ravensburger is a decision-making game in which the players were challenged to achieve the highest total score by making the longest colored lines on a hexagonal game board. "The Traffic and I" from Jumbo is a Dutch equivalent of the Road Sign Recognition task of the Stroke Driver Screening Assessment. ${ }^{18}$ Participants were asked to match road signs with traffic situations. The last cognitive intervention was a route finding task in which the participants needed to draw on a sheet of paper the most efficient route to different well-known target locations, taking into account the distance and the time of traveling. 


\section{Evaluation}

A full description of the visual and neuropsychological tests can be found in the original RCT. ${ }^{10}$ On-road driving performance was assessed before, immediately after training, and at 6 months poststroke using the Test Ride for Investigating Practical fitness to drive (TRIP)-Belgian version. ${ }^{19}$ The TRIP checklist is part of the fitness to drive assessment protocol of the Center for Fitness to Drive Evaluation and Car Adaptations (CARA) of the Belgian Road Safety Institute. The TRIP checklist was administered by occupational and physical therapists with expertise in evaluating fitness to drive in people with neurological conditions. The CARA assessors were blind to group allocation. The reliability and validity of this on-road checklist have been established earlier. ${ }^{20,21}$ The TRIP consists of 13 items and 49 subitems and is scored on a 4-point ordinal scale of 1 = poor, 2 = insufficient, $3=$ sufficient, and 4 = good, giving a total range from 49 to 196 .

The 13 items of the TRIP are closely linked to the hierarchic structure of the driving task ${ }^{22}$ and can be clustered into 4 categories as adapted from De Raedt and Ponjaert-Kristoffersen. ${ }^{19}$ The operational cluster consists of position on the road at speed (I) below and (II) above $50 \mathrm{~km} / \mathrm{h}$ and (III) mechanical operations. It reflects psychomotor aspects of driving and includes splitsecond operations of the steering wheel and pedals. ${ }^{19,22}$ The tactical cluster comprises speed (IV) below and (V) above 50 $\mathrm{km} / \mathrm{h}$, distance from car ahead at speed (VI) below and (VII) above $50 \mathrm{~km} / \mathrm{h}$, and (VIII) lane position change. This cluster reflects functions that need to be executed in a few seconds and requires sustained attention, flexibility, adaptation strategies, and adequate judgment. ${ }^{19,22}$ The visuointegrative cluster comprises (IX) anticipation and perception of signs, (X) visual behavior and communication, and (XI) quality of traffic participation. It reflects visuospatial aspects, visuoperceptual aspects, and higher-order cognitive processes. ${ }^{19}$ The mixed cluster consists of (XII) joining the traffic stream and (XIII) turning left. It includes a combination of operational, tactical, and visuointegrative skills. ${ }^{19}$

All procedures were in accordance with ethical standards of human experimentation and approved by the Medical Ethics Committee of the University Hospitals Leuven, Belgium.

\section{Data Analysis}

Participants' baseline characteristics were explored for normality using the Kolmogorov-Smirnov test. Participants' total score on the TRIP checklist and the scores on its items as well as its clusters were compared within and between groups using a generalized estimating equation (GEE) with an independent link. ${ }^{23}$ The TRIP scores were categorized into 3 classes that were based on clinical and scientific criteria. ${ }^{6}$ Scores below $65 \%$ of the maximum performance were attributed to the first category. The third category consisted of the maximum scores. The second category comprised all in-between scores. The variables group, time, and the interaction term group $\times$ time were entered into the model. The corrected quasi-likelihood under independence criterion, an estimation of the goodness of fit of the GEE model, was always better with the interaction effect included in the model. The time effect investigated the progression of the TRIP scores over time in both groups, whereas the interaction effect looked at the differential effect of the 2 driving training programs over time. The response variables were the total score, the clusters, and the 13 items of the TRIP checklist. The GEE model excludes cases for which the response variable is missing (ie, the road items). Therefore, the scores of the participants who were lost to follow-up at 6 months poststroke were retained by imputing the median of each group. Intention-to-treat analysis was performed to investigate the effect of eliminating data sets of the participants who dropped out during the study period.

Bonferroni correction for multiple testing was applied for the items of each cluster. For all other tests, $P$ values $<.05$ were considered significant.

All basic statistical procedures were performed with the statistical programs SAS 9.1 and SAS Enterprise Guide 4.0. The GEE analyses were performed with the Statistical Package for the Social Sciences (SPSS), version 15.0.

\section{Results}

\section{Subjects}

Throughout the 20-month recruitment period, 101 participants hospitalized in the University Hospital Pellenberg met the inclusion criteria. Eighty-three participants $(82 \%)$ consented and were randomized into 2 intervention programs. Forty-two participants received simulator-based training; 41 received cognitive training. During the training program, 5 participants in each group were lost. Reasons for dropout during training were medical $(n=3)$, early discharge $(n=2)$, age $(\mathrm{n}=3)$, and confidentiality $(\mathrm{n}=2)$. Data analysis was therefore conducted on the 73 subjects (59 men, 14 women) who completed the intervention. At 6 months poststroke, 11 more participants were lost in the simulator group, and another 10 were lost in the cognitive group..$^{10}$ Reasons for dropout at followup were medical $(n=6)$, refusal $(n=7)$, and out of time frame $(\mathrm{n}=8)$. Subjects included in this study were stroke survivors without severe deficits. They were 6 to 9 weeks after stroke onset and were independently ambulant, with or without assistive advices (cane or wheelchair). They were on average $54 \pm$ 12 years of age, had $33 \pm 11$ years of driving experience, drove $24000 \pm 15000 \mathrm{~km}$ in the year previous to the event, and had a Barthel score of $74 \pm 26$. The median MMSE score was 30 (27-30). Fourteen (19\%) from the 73 subjects presented with visual field loss, 19 (26\%) with visual inattention, and $15(21 \%)$ with tactile inattention. Fifty-six (77\%) suffered from an ischemic infarct and $17(23 \%)$ a hemorrhagic infarct. Thirty-two (44\%) had a left-sided lesion, $38(52 \%)$ a rightsided lesion, and $3(4 \%)$ a bilateral lesion. Thirty-nine (53.5\%) 
Figure 1

Median and Interquartile Range of the Total On-Road Performance (TRIP Checklist) for the Simulator Training Group $(n=37)$ and the Cognitive Training Group $(n=36)$ Before Intervention, Immediately After Intervention, and at 6-Month Follow-up

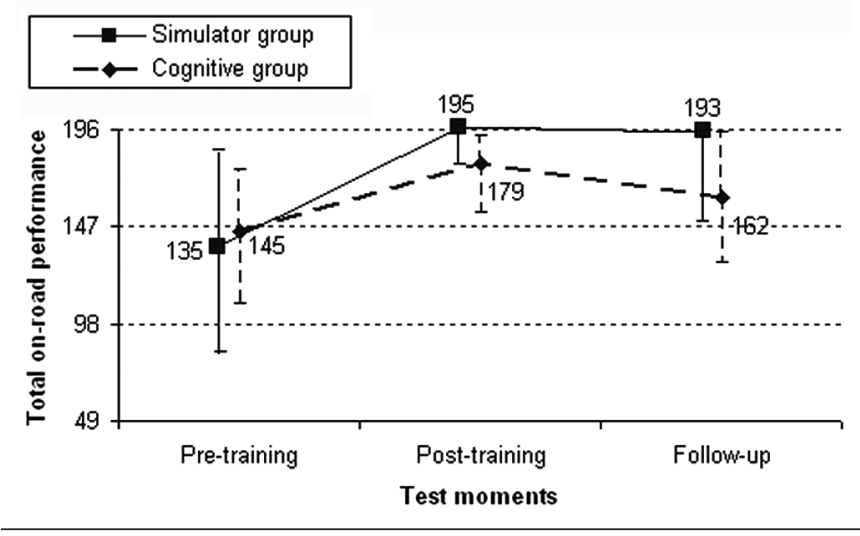

had higher education, 28 (38.5\%) secondary education, and 6 (8\%) elementary education. Descriptive characteristics (age, sex, education, driving experience, and driving distance) and clinical characteristics (Barthel Index, MMSE, visual field loss, visual and tactile inattention, type of stroke, and side of lesion) did not differ between groups. ${ }^{10}$

\section{Specificity of the Driving Retraining Programs}

Figure 1 shows the medians and interquartile ranges of the total TRIP score for the 37 participants from the simulator training group and 36 participants from the cognitive training group before training, after training, and at 6 months follow-up. There were no differences between the 2 groups for the initial TRIP score. Both groups improved considerably from pretraining to posttraining. The improvement from posttraining to follow-up remained stable for the simulator training group. The scores on the TRIP deteriorated in the cognitive training group.

Tables 1 and 2 show the results of the GEE analysis. Overall, both groups improved their performance over time on all aspects of on-road performance, though the pattern of progression differed sometimes between both groups.

Looking more in detail, a significant interaction effect of group $\times$ time was found for the total on-road score (Table 1). Post hoc GEE comparisons revealed that participants in the simulator training group improved more on the TRIP total score than their peers in the cognitive training group 6 months after stroke onset $(\beta=.502$; confidence interval $[\mathrm{CI}]=0.148$ $0.856 ; P=.005)$.

No interaction effect was found for the score on the operational cluster (Table 1). The $P$ value, however, was borderline significant $(P=.06)$. Similarly, no interaction effects were found for any of the 3 individual operational items (Table 2).
Table 1

Results of Generalized Estimating Equation for the Total On-Road Performance and the Clusters of Items in 73 Stroke Subjects ${ }^{\mathrm{a}}$

\begin{tabular}{llrlc}
\hline & & \multicolumn{2}{c}{ Tests of Model Effects } \\
\cline { 3 - 5 } Response & & & & \\
\cline { 3 - 5 } Variable & Variable & Wald $\chi^{2}$ & df & $P$ Value \\
\hline Overall performance & Intercept & 1234.60 & 1 & $<.0001$ \\
& Group & 6.10 & 1 & .01 \\
& Time & 61.79 & 2 & $<.0001$ \\
& Group $\times$ Time & 8.71 & 2 & .01 \\
1. Operational & Intercept & 891.07 & 1 & $<.0001$ \\
cluster & Group & 4.67 & 1 & .03 \\
& Time & 65.97 & 2 & $<.0001$ \\
2. Tactical cluster & Group $\times$ Time & 5.62 & 2 & .06 \\
& Intercept & 1019.79 & 1 & $<.0001$ \\
& Group & 3.95 & 1 & .05 \\
& Time & 53.03 & 2 & $<.0001$ \\
3. Visuointegrative & Group $\times$ Time & 10.03 & 2 & .01 \\
cluster & Intercept & 1079.02 & 1 & $<.0001$ \\
& Group & 6.96 & 1 & .01 \\
& Time & 40.76 & 2 & $<.0001$ \\
4. Mixed cluster & Group $\times$ Time & 7.55 & 2 & .02 \\
& Intercept & 1092.01 & 1 & $<.0001$ \\
& Group & 4.23 & 1 & .04 \\
& Time & 25.82 & 2 & $<.0001$ \\
& Group $\times$ Time & 4.46 & 2 & .11 \\
\hline
\end{tabular}

Abbreviation: df, degree of freedom.

${ }^{\text {a }}$ Specificity of the driving retraining program was examined by the interaction effect group $\times$ time.

A significant interaction effect was found for the score on the tactical cluster (Table 1). Participants who received simulator training improved more than their peers at posttraining $(\beta=.372$; $\mathrm{CI}=0.162-0.550 ; P=.02)$ and at follow-up $(\beta=.531 ; \mathrm{CI}=0.151-$ $0.911 ; P=.006)$. However, results on tactical items individually did not reveal any interaction effect (Table 2).

A significant interaction effect was found for the score on the visuointegrative cluster (Table 1). Participants from the simulator group benefited more from their training program than their comparison group. However, the difference was only significant at 6-month follow-up $(\beta=.558$; CI $=0.159$ $0.957 ; P=.006)$. Similarly, significant interaction effects were found for all the visuointegrative items (see Table 2). The simulator group improved more than the cognitive group on those items, but only at follow-up $(\beta=.668, C I=0.269-1.068$, $P=.001$ for the item anticipation and perception of signs; $\beta=$ $.725, \mathrm{CI}=0.279-1.172, P=.002$ for the item visual behavior and communication; and $\beta=.664, \mathrm{CI}=0.226-1.101, P=.002$ for the item quality of traffic participation). Furthermore, participants who received simulator training scored better than their peers on the item quality of traffic participation immediately after training $(\beta=.452, \mathrm{CI}=0.022-0.882, P=.04)$.

For the mixed cluster, no significant interaction effect was found for the total score (Table 1). Results on the item turning left showed an interaction effect (Table 2), with participants from 
Table 2

Results of Generalized Estimating Equation for the Items
of the On-Road TRIP Checklist in 73 Stroke Subjects ${ }^{\text {a }}$

\begin{tabular}{|c|c|c|c|c|}
\hline \multirow[b]{2}{*}{ Response Variable } & \multicolumn{4}{|c|}{ Tests of Model Effects } \\
\hline & Variable & Wald $\chi^{2}$ & df & $P$ Value \\
\hline \multicolumn{5}{|l|}{ Operational cluster ${ }^{\mathrm{b}}$} \\
\hline \multirow{4}{*}{$\begin{array}{l}\text { 1. Position on the road } \\
\text { at }<50 \mathrm{~km} / \mathrm{h}\end{array}$} & Intercept & 848.34 & 1 & $<.0001$ \\
\hline & Group & 5.70 & 1 & .02 \\
\hline & Time & 70.15 & 2 & $<.0001$ \\
\hline & Group $\times$ Time & 4.32 & 2 & .12 \\
\hline \multirow{4}{*}{$\begin{array}{l}\text { 2. Position on the } \\
\text { road at }>50 \mathrm{~km} / \mathrm{h}\end{array}$} & Intercept & 781.56 & 1 & $<.0001$ \\
\hline & Group & 5.20 & 1 & .02 \\
\hline & Time & 61.78 & 2 & $<.0001$ \\
\hline & Group $\times$ Time & 4.66 & 2 & .10 \\
\hline \multirow{4}{*}{$\begin{array}{l}\text { 3. Mechanical } \\
\text { operations }\end{array}$} & Intercept & 1074.30 & 1 & $<.0001$ \\
\hline & Group & 0.09 & 1 & .46 \\
\hline & Time & 27.18 & 2 & $<.0001$ \\
\hline & Group $\times$ Time & 1.35 & 2 & .51 \\
\hline \multicolumn{5}{|l|}{ Tactical cluster ${ }^{\mathrm{c}}$} \\
\hline \multirow{4}{*}{$\begin{array}{l}\text { 4. Speed in areas with } \\
\text { limit }<50 \mathrm{~km} / \mathrm{h}\end{array}$} & Intercept & 1112.34 & 1 & $<.0001$ \\
\hline & Group & 0.26 & 1 & .61 \\
\hline & Time & 47.02 & 2 & $<.0001$ \\
\hline & Group $\times$ Time & 0.22 & 2 & .90 \\
\hline \multirow{4}{*}{$\begin{array}{l}\text { 5. Speed in areas with } \\
\text { limit }>50 \mathrm{~km} / \mathrm{h}\end{array}$} & Intercept & 1129.30 & 1 & $<.0001$ \\
\hline & Group & 1.20 & 1 & .27 \\
\hline & Time & 55.02 & 2 & $<.0001$ \\
\hline & Group $\times$ Time & 1.27 & 2 & .53 \\
\hline \multirow{4}{*}{$\begin{array}{l}\text { 6. Distance from car } \\
\text { ahead at }<50 \mathrm{~km} / \mathrm{h}\end{array}$} & Intercept & 1445.98 & 1 & $<.0001$ \\
\hline & Group & 1.30 & 1 & .25 \\
\hline & Time & 54.86 & 2 & $<.0001$ \\
\hline & Group $\times$ Time & 2.22 & 2 & .33 \\
\hline \multirow{4}{*}{$\begin{array}{l}\text { 7. Distance from car } \\
\text { ahead at }>50 \mathrm{~km} / \mathrm{h}\end{array}$} & Intercept & 1311.24 & 1 & $<.0001$ \\
\hline & Group & 1.26 & 1 & .26 \\
\hline & Time & 52.90 & 2 & $<.0001$ \\
\hline & Group $\times$ Time & 1.47 & 2 & .48 \\
\hline \multirow[t]{4}{*}{ 8. Lane position change } & Intercept & 1196.58 & 1 & $<.0001$ \\
\hline & Group & 4.04 & 1 & .05 \\
\hline & Time & 31.42 & 2 & $<.0001$ \\
\hline & Group $\times$ Time & 3.00 & 2 & .22 \\
\hline \multicolumn{5}{|l|}{ Visuointegrative cluster ${ }^{\mathrm{b}}$} \\
\hline \multirow{4}{*}{$\begin{array}{l}\text { 9. Anticipation and } \\
\text { perception of signs }\end{array}$} & Intercept & 988.24 & 1 & $<.0001$ \\
\hline & Group & 2.11 & 1 & .15 \\
\hline & Time & 46.17 & 2 & $<.0001$ \\
\hline & Group $\times$ Time & 11.03 & 2 & $<.0001$ \\
\hline \multirow{4}{*}{$\begin{array}{l}\text { 10. Visual behavior } \\
\text { and communication }\end{array}$} & Intercept & 1011.62 & 1 & $<.0001$ \\
\hline & Group & 8.48 & 1 & $<.0001$ \\
\hline & Time & 21.89 & 2 & $<.0001$ \\
\hline & Group $\times$ Time & 10.16 & 2 & .006 \\
\hline \multirow{4}{*}{$\begin{array}{l}\text { 11. Quality of traffic } \\
\text { participation }\end{array}$} & Intercept & 959.88 & 1 & $<.0001$ \\
\hline & Group & 8.36 & 1 & $<.0001$ \\
\hline & Time & 52.44 & 2 & $<.0001$ \\
\hline & Group $\times$ Time & 9.78 & 2 & .008 \\
\hline \multicolumn{5}{|l|}{ Mixed cluster $^{\mathrm{d}}$} \\
\hline \multirow{4}{*}{$\begin{array}{l}\text { 12. Joining the } \\
\text { traffic stream }\end{array}$} & Intercept & 938.94 & 1 & $<.0001$ \\
\hline & Group & 5.61 & 1 & .02 \\
\hline & Time & 31.76 & 2 & $<.0001$ \\
\hline & Group $\times$ Time & 5.06 & 2 & .08 \\
\hline 13. Turning left & Intercept & 1066.44 & 1 & $<.0001$ \\
\hline & Group & 4.01 & 1 & .05 \\
\hline & Time & 22.58 & 2 & $<.0001$ \\
\hline & Group $\times$ Time & 6.80 & 2 & .02 \\
\hline
\end{tabular}

Abbreviations: TRIP, Test Ride for Investigating Practical fitness to drive; df, degree of freedom.

${ }^{a}$ Specificity of the driving retraining program was examined by the interaction effect group $\times$ time.

${ }^{\mathrm{b}} P<.017(0.05 / 3)$ was considered significant after Bonferroni correction.

${ }^{\mathrm{c}} P<.01(0.05 / 5)$ was considered significant after Bonferroni correction.

${ }^{\mathrm{d}} P<.025(0.05 / 2)$ was considered significant after Bonferroni correction. the simulator group performing better at follow-up than those from the cognitive group $(\beta=.589, \mathrm{CI}=0.138-1.039, P=.01)$.

Intention-to-treat analysis showed that the results of the dropouts did not change the results obtained.

\section{Discussion}

This study constituted an item-per-item analysis of an earlier RCT, investigating the effect of simulator-based therapy on overall driving performance in stroke survivors with mild to moderate deficits. ${ }^{10}$ The present study further analyzed the specific effects of 2 driving retraining programs, representing different concepts of rehabilitation of on-road driving skills after stroke. Driving simulator training focuses on task-specific training in a functional context. Cognitive training addresses the cognitive skill components necessary for safe driving, assuming a carryover effect into on-road driving performance.

Overall it was found that performance on the on-road test and 4 of its items, that is, (1) anticipation and perception of road signs, (2) visual behavior and communication, (3) quality of traffic participation, and (4) turning left improved significantly more in the simulator group than in the cognitive group. Therefore, our results partly support the hypothesis that the rehabilitation of driving skills after stroke should focus on direct training of functional skills rather than its components. ${ }^{24}$ The lack of carryover effect by training driving skills through cognitive component training has also been found in another study. $^{9}$

Driving simulator therapy showed to be superior to cognitive training with regard to overall on-road performance. This confirms earlier studies that driving simulator skills can be generalized to real-world driving. ${ }^{10,25-27}$ Driving simulator therapy could therefore substantially increase the proportion of stroke survivors who pass an official driving assessment, especially in countries in which the on-road test is the only criterion of fitness to drive. ${ }^{1-4,13,14}$

However, not all on-road aspects can be trained equally well through simulator therapy. Items involving operational maneuvers such as positioning on the road, steering, and pedaling only showed a trend toward better improvement in the simulator training group. This was a surprise as participants in the simulator group not only practiced operational skills in a functional context but also specifically learned to use car adaptations in anticipation for the on-road test. Participants in the cognitive training group with loss of functioning in the hemiplegic side only got the opportunity to familiarize with the car adaptations prior to the evaluation on the road. A possible explanation might be that operational skills are too basic to benefit from a simulator-based driving retraining program for this group of patients.

The tactical cluster produced significant interaction effects immediately after training as well as at follow-up, indicating that simulator-based therapy offered more positive transfer of tactical on-road skills. However, the improvement in the individual items of the tactical cluster did not show a difference between the 2 intervention programs. Combining several 
aspects assessing the same driving skills obviously increased the statistical power to demonstrate differences between the 2 interventions. This finding is further supported by KornerBitensky et al, ${ }^{4}$ who found that the evaluation of on-road skills cannot be predicted by only one variable.

Simulator training had more effect than cognitive training on all visuointegrative items. Differences between intervention groups were only found at follow-up assessment, with the exception of the item quality of traffic participation. The simulator training group also performed better on this item immediately after training. It might be that visuointegrative skills learned in a virtual environment require some time to consolidate in real-life practice.

It appears that the ability to perceive and integrate visual information into appropriate nonverbal communication and a better insight in traffic situations can be trained more efficiently in a driving simulator. Attention and visuospatial deficits have been found difficult to train by conventional methods in other studies, ${ }^{9,28,29}$ which increase the clinical relevance of the present findings. We particularly found that the simulator group responded better to road signs and traffic signals during on-road driving. This was surprising because the cognitive training group was specifically trained on road sign recognition tasks. Our findings indicate that simulator therapy has a positive transfer effect of road sign recognition skills, measured during real-life driving performance.

The fact that the item turning left was performed better after simulator therapy is important as this item has been recognized as one of the most difficult traffic maneuvers. ${ }^{30,31}$ Moreover, there is an overrepresentation of older adults in fatal car accidents that occur while turning left at intersections. ${ }^{30,31}$ The current results suggest that driving simulator training can provide a way to train this specific item.

There are some limitations to this study. In contrast to the driving simulator scenarios, most of the cognitive games did not increase in complexity. It was therefore impossible for a small number of participants in the cognitive group to further improve once they achieved the maximal level of performance. Divided attention, one of the key skills of driving ability, ${ }^{32}$ was not explicitly trained in the cognitive training group, whereas the simulator training group received specific training of divided attention on top of the training of each driving skill. The TRIP has a ceiling effect, which made it impossible to improve for $25 \%$ of the simulator group from posttraining to follow-up. Despite the ceiling effect, significant interaction effects were found, which suggest that crude differences in improvements occurred between interventions. The high dropout rate cannot be ignored. Ten of the 83 (12\%) participants did not finish either of the 2 intervention programs, and 31 $(37 \%)$ were not assessed at long term. However, results of the intention-to-treat analysis showed that dropout occurred completely at random.

It would be interesting to see whether these results can be generalized to other neurological conditions such as brain injuries and Parkinson disease. Future studies should also focus on the effects of driving simulator therapy on traffic participation in the long term.

\section{Acknowledgments}

The authors thank the participants for their time and cooperation to participate in this study. They are also grateful to the CARA staff of the Belgian Road Safety Institute for their expert advice. This study was funded by a grant from Stichting Van Goethem-Brichant, the Interfaculty Institute for Development Cooperation, and the Department of Rehabilitation Sciences of the Katholieke Universiteit Leuven. The authors report no conflict of interest.

\section{References}

1. Nouri FM, Lincoln NB. Predicting driving performance after stroke. BMJ. 1993;307:482-483.

2. Mazer BL, Korner-Bitensky NA, Sofer S. Predicting ability to drive after stroke. Arch Phys Med Rehabil. 1998;79:743-750.

3. Lundqvist A, Gerdle B, Rönnberg J. Neuropsychological aspects of driving after stroke-in the simulator and on the road. Appl Cogn Psychol. 2000;14:135-150.

4. Korner-Bitensky N, Mazer BL, Sofer S, et al. Visual testing for readiness to drive after stroke. Am J Phys Med Rehabil. 2000;79:253-259.

5. Akinwuntan AE, Feys H, De Weerdt W, Baten G, Arno P, Kiekens C. Prediction of driving after stroke: a prospective study. Neurorehabil Neural Repair. 2006;20:417-423.

6. Akinwuntan AE, Devos H, Feys H, et al. Confirmation of the accuracy of a short battery to predict fitness-to-drive of stroke survivors without severe deficits. J Rehabil Med. 2007;39:698-702.

7. Legh-Smith J, Wade DT, Hewer RL. Driving after a stroke. J R Soc Med. 1986;79:200-203.

8. Ragland DR, Satariano WA, MacLeod KE. Driving cessation and increased depressive symptoms. J Gerontol A Biol Sci Med Sci. 2005;60:399-403.

9. Mazer BL, Sofer S, Korner-Bitensky N, Gelinas I, Hanley J, WoodDauphinee $\mathrm{S}$. Effectiveness of a visual attention retraining program on the driving performance of clients with stroke. Arch Phys Med Rehabil. 2003;84:541-550.

10. Akinwuntan AE, De Weerdt W, Feys H, et al. Effect of simulator training on driving after stroke: a randomized controlled trial. Neurology. 2005;65:843-850.

11. Ball KB, Roenker DL, Bruni JR. Developmental changes in attention and visual search throughout adulthood. In: Enns J, ed. The Development of Attention: Research and Theory. Amsterdam, the Netherlands: Elsevier Science; 1990:489-508.

12. Akinwuntan AE, Feys H, De Weerdt W, Pauwels J, Baten G, Strypstein E. Determinants of driving after stroke. Arch Phys Med Rehabil. 2002;83: 334-341.

13. Nouri FM, Tinson DJ, Lincoln NB. Cognitive ability and driving after stroke. Int Disabil Stud. 1987;9:110-115.

14. Lundberg C, Caneman G, Samuelsson SM, Hakamies-Blomqvist L, Almkvist $\mathrm{O}$. The assessment of fitness to drive after a stroke: the Nordic Stroke Driver Screening Assessment. Scand J Psychol. 2003;44:23-30.

15. Van den Meerschaut C. Rijgeschiktheid. Semper. 1998;226:1-35.

16. Hsieh YW, Wang CH, Wu SC, Chen PC, Sheu CF, Hsieh CL. Establishing the minimal clinically important difference of the Barthel Index in stroke patients. Neurorehabil Neural Repair. 2007;21:233-238.

17. Folstein M, Folstein S, McHugh P. Mini-Mental State: a practical method for grading the cognitive state of patients for the clinician. $J$ Psychiatric Res. 1975;12:189-198. 
18. Nouri FM, Lincoln NB. Validation of a cognitive assessment: predicting driving performance after stroke. Clin Rehabil. 1992;6:275-281.

19. De Raedt R, Ponjaert-Kristoffersen I. Predicting at-fault car accidents of older drivers. Accid Anal Prev. 2001;33:809-819.

20. Akinwuntan AE, De Weerdt W, Feys H, Baten G, Arno P, Kiekens C. Reliability of a road test after stroke. Arch Phys Med Rehabil. 2003;84:1792-1796.

21. Akinwuntan AE, De Weerdt W, Feys H, Baten G, Arno P, Kiekens C. The validity of a road test after stroke. Arch Phys Med Rehabil. 2005;86:421-426.

22. Michon JA. Explanatory pitfalls and rule-based driver models. Accid Anal Prev. 1989;21:341-353.

23. Zeger SL, Liang KY, Albert PS. Models for longitudinal data: a generalized estimating equation approach. Biometrics. 1988;44:1049-1060.

24. Carr J, Shepherd R. Movement Science: Foundations for Physical Therapy in Rehabilitation. 2nd ed. Gaithersburg, MD: Aspen; 2000.

25. Kewman DG, Seigerman C, Kintner H, et al. Simulation training of psychomotor skills: teaching the brain-injured to drive. Rehab Psychol. 1985;30:11-27.
26. Cimolino N, Balcovec D. The contribution of a driving simulator in the driving evaluation of stroke and disabled adolescent clients. Can J Occup Ther. 1988;55:119-125.

27. Kent H, Sheridan J, Wasko E, June C. A driver training program for the disabled. Arch Phys Med Rehabil. 1979;60:273-276.

28. Cicerone KD, Dahlberg C, Malec JF, et al. Evidence-based cognitive rehabilitation: updated review of the literature from 1998 through 2002. Arch Phys Med Rehabil. 2005;86:1681-1692.

29. Park NW, Ingles JI. Effectiveness of attention rehabilitation after acquired brain injury: a meta-analysis. Neuropsychology. 2001;15:199-210.

30. Hakamies-Blomqvist L. Compensation in older drivers as reflected in their fatal accidents. Accid Anal Prev. 1994;26:107-112.

31. McGwin G Jr, Brown DB. Characteristics of traffic crashes among young, middle-aged, and older drivers. Accid Anal Prev. 1999;31:181-198.

32. Lezak MD. Neuropsychological Assessment. New York, NY: Oxford University Press; 1995.

For reprints and permission queries, please visit SAGE's Web site at http://www.sagepub.com/journalsPermissions.nav 